\title{
La influencia cultural a través de la música mexicana: rancheras en Chile
}

\author{
Luis Omar Montoya Arias y Karla Liebed Solís García
}

\begin{abstract}
Resumen
Durante años, el contenido transmitido en los medios de comunicación, especialmente la radio, ha permitido conocer diferentes tipos de música alrededor del mundo. Este fue el caso de las rancheras, un género popular originario de México que los músicos chilenos adecuaron de acuerdo con su contexto y tradiciones, lo que gradualmente permitió solidificar su identidad. Esta expansión cultural de la música originó, en Chile, confrontaciones entre músicos y el Estado debido a los acontecimientos políticos provocados por la dictadura pinochetista en la década de los setenta. Este período se caracterizó por privaciones de intercambio cultural, censura de material discográfico, desequilibrio económico, entre otros.
\end{abstract}

Palabras clave: medios de comunicación, rancheras, México, Chile, dictadura pinochetista, intercambio cultural, censura, desequilibrio económico.

\section{Cultural influence through Mexican music: rancheras in Chile}

\begin{abstract}
For years, the content transmitted in the different media, especially radio, has allowed us to become acquainted with different types of music around the world. This is the case of the rancheras, a popular genre from Mexico that Chilean musicians adapted according to their context and traditions, which gradually allowed the solidification of its identity. This cultural expansion in Chile caused confrontations between musicians and the State, due to the political events that the Pinochet dictatorship in the 1970s had generated. This period was characterized by deprivations of cultural exchange, censorship of record material, economic imbalance, among others.
\end{abstract}

Keywords: media, rancheras, Mexico, Chile, Pinochet dictatorship, cultural exchange, censorship, economic imbalance. 


\section{Luis Omar Montoya Arias}

luisomarmontoyaarias1982@gmail.com https://orcid.org/0000-0003-3143-9959

Doctor en Historia por el CIESAS. Científico. Historiador social y cultural. Docente en distintos niveles educativos. Profesor en el sistema público y en el privado. Miembro del Sistema Nacional de Investigadores de México (CONACYT). Académico invitado en programas de Javier Solórzano (canal 11)y Enrique Lazcano (canal 14). Investigador social, docente universitario y conferencista. Especialista en América Latina. Producción y locución radiofónica. Versado en música mexicana. Asesoría histórica de documentales (La Ley del Corrido para Discovery / y El Mariachi para History, como ejemplos emblemáticos). Habilidades como analista político. Catalogación de archivos históricos. Autor de libros de investigación social publicados por editoriales de prestigio y de artículos indexados en revistas académicas. Editorialista en el Periódico am de Guanajuato. Productor de Diálogos con las músicas populares mexicanas, transmitido por Radio Universidad de Guanajuato (2015-2017). Ha realizado estancias de investigación en Estados Unidos, Chile, Colombia, Brasil y Bolivia.

\section{Karla Liebed Solís García}

liebedsolis1@gmail.com https://orcid.org/0000-0001-6378-8016

Licenciada en Pedagogía, egresada de la Universidad Pedagógica Nacional, Unidad Ajusco, Área Académica 5: Teoría Pedagógica y Docente; y del Cuerpo Académico: Historia de la Educación y Educación Histórica UPN-CA-113. Interesada en estudios de historia de la educación de los libros de texto gratuitos y su labor en las aulas mexicanas como medio de aprendizaje. Ha participado en congresos y simposios relacionados con la investigación histórica y la investigación educativa. 
"La influencia cultural a través de la música mexicana: rancheras en Chile" Luis Omar Montoya Arias y Karla Liebed Solís García

Nibaldo Valenzuela Fernández, coleccionista chileno de música mexicana, recuerda que el golpe militar empezó a las 8 a.m. del 11 de septiembre de 1973. Él iba a trabajar y de pronto comenzó a ver militares por todos lados, aviones sobrevolando Santiago. Desde las 6 a.m. las radios informaron que La Moneda estaba rodeada. Al llegar a la fábrica donde laboraba, Valenzuela Fernández encontró la entrada bloqueada por militares y carabineros. Como a las 10 a.m. se avisó por la radio: "nos hemos dado cuenta que hay un golpe militar, el gobierno de Salvador Allende será derrocado por las fuerzas militares" (Valenzuela, 2013).

\section{Reprimen a las músicas mexicanas}

El 29 de junio de 1973, ocurrió el primer intentó de derrocamiento contra el gobierno de la Unidad Popular, encabezado por Salvador Allende. Al acontecimiento se le conoce como Tanquetazo o Tancazo. La sublevación fue sofocada por el General Carlos Prats. Una semana después de acontecido, el dueto chileno de música norteña mexicana, bautizado como Los Tejanos de América y su disquera Sol de América pusieron a circular el corrido: "Gesta Heroica". 1Éste, junto con "El Animalito" con Los Luceros del Valle (1975) y "La Pirilacha" con Nilda Moya (1978) fueron censurados por la dictadura pinochetista.

En realidad, el corrido no fue el único género prohibido por el gobierno de Augusto Pinochet Ugarte, la cumbia fue otra de las víctimas musicales. Los Luceros del Valle, el dueto chileno de música norteña mexicana más influyente, integrado por Rafael Alcaino Leyva y Oscar Inzunza, lo vivió en carne propia con su canción "El Animalito", ya que la esposa de Pinochet prohibió esta melodía bajo el argumento de "atentar contra la moral y buenas costumbres" (Inzunza, 2012). No obstante, fueron galardonados por Sol de América, gracias al éxito de la canción.

Mientras"Gesta heroica" fue censurado por cuestiones políticas, la represión hacia El Animalito y La Pirilacha obedeció a temas morales. "La composición del Animalito fue la primera en su especie; el gobierno militar la censuró porque en esos tiempos la Iglesia Católica tenía mucho poder. Otra canción prohibida fue' El chinito constructor' con Los Luceros del Valle" (Valenzuela, 2012).

1 El corrido dice textualmente: "Un 29 de junio sin que nadie lo creyera / un regimiento blindado formaba una balacera / los tanques que dirigía un jefe insubordinado / disparaban a matar a civiles y soldados / A derrocar el gobierno salieron una mañana / pero las tropas leales les quitaron esas ganas / dos horas de balacera y momentos de tensión / pidiendo los insurgentes a La Moneda su rendición / A la mierda el enemigo, nadie nos puede vencer".

\section{El disco}

La dictadura afectó a la música mexicana en Chile, modificó sus circuitos de movilidad y llevó al cierre de disqueras trasnacionales establecidas en Santiago. Con el golpe militar dejaron de llegar discos de música mexicana. "Los que podías conseguir, ingresaron antes de la dictadura" (Valenzuela, 2012). El coleccionista Nibaldo Valenzuela Fernández recuerda que adquirió un LP de Los Tremendos Gavilanes en 1975. Éste fue traído de California, en un lote ingresado a Chile, en 1972. "Las disqueras vendieron lo que les quedaba y se fueron de Chile. En 1980, los discos de músicas mexicanas estaban agotados" (Valenzuela, 2013). 
Imagen 1. Íconos mexicanos. Recuperado de: https://www. pinterest.com.mx/pin/48519255 9850023672/?|p=true.
Para 1973, año en que comenzó la dictadura pinochetista, el gusto por la música estaba en todo Chile. Existía un mercado consumidor que fue aprovechado por empresarios chilenos en la consolidación de su industria discográfica. Si bien, sellos como Asfona y Sol de América nacieron en 1963 y 1972, respectivamente, fue en la dictadura que alcanzaron sus niveles más altos de productividad. Asfona tenía a Los Hermanos Bustos, pioneros de la música norteña mexicana hecha por chilenos; por otro lado, Sol de América presumía la exclusividad de Los Luceros del Valle, originarios de Rancagua (a dos horas de Santiago). Los Hermanos Bustos se nutrieron de Los Broncos de Reynosa y Los Alegres de Terán. Los Luceros del Valle son los padres de la cumbia ranchera.

Sol de América se ubicó sobre la Gran Avenida. Gracias a esta empresa, la música mexicana que entró antes del golpe fue regrabada en casete. Valenzuela recuerda haber comprado casetes de Antonio Aguilar y Mercedes Castro, editados por Sol de América, en la década de 1970. También hubo radios como Sargento Candelaria que pusieron a la venta su acervo de música mexicana.

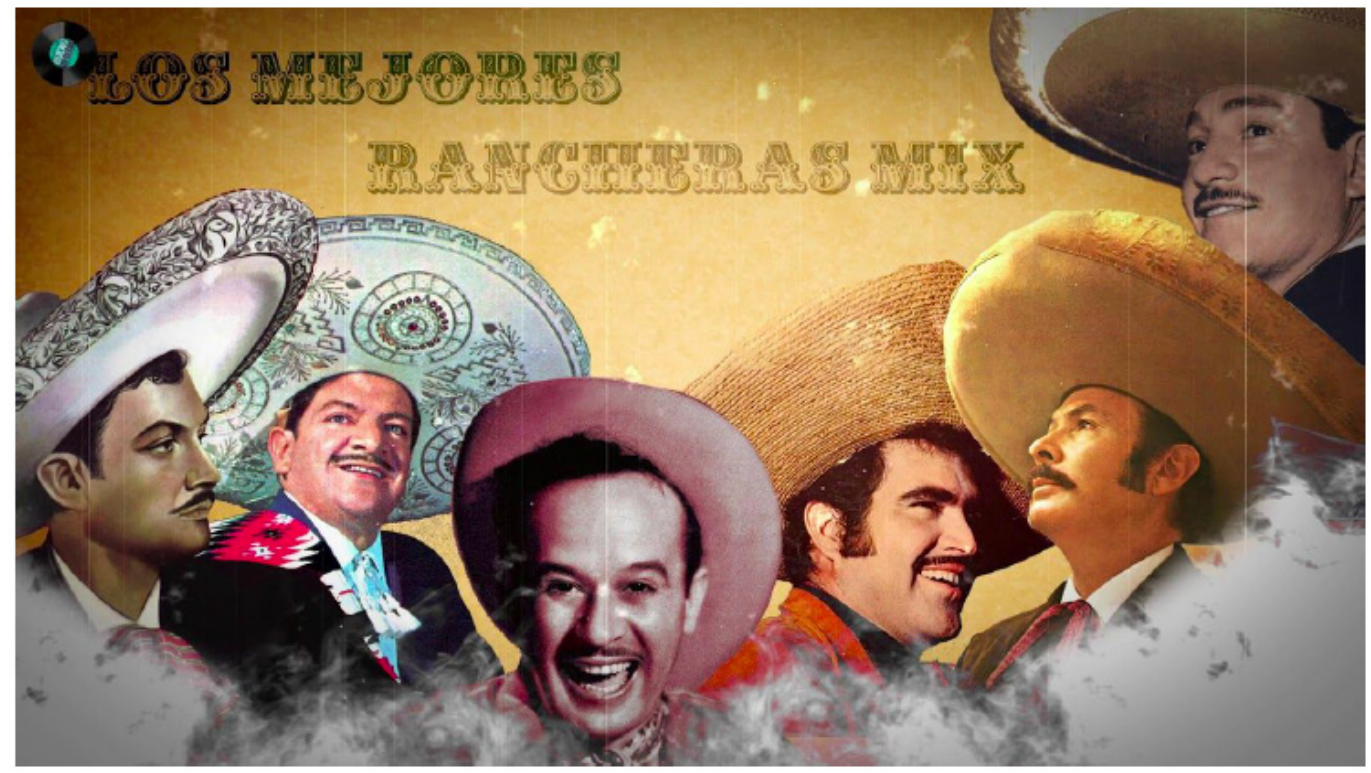

Debido al consumo de músicas mexicanas, chilenos como Nibaldo Valenzuela aprovecharon los circuitos migratorios que el entorno laboral les brindó:

Me acuerdo que en 1964, aparecían personas en revistas que deseaban entrar en contacto con personas de otros países, entonces le escribí y me salió una niña hija del presidente municipal de Valle Hermoso, Tamaulipas. Conversamos por cartas. Ella me mandó un disco de Las Hermanas Padilla y otro de Las Jilguerillas que traía dos canciones por cada lado: Ojitos encantadores, boquita coloradita, Ojitos aceitunados, Llorar y llorar. Los dejé en Curicó. Mi hermano que no tenía música, sacaba los discos a sus fiestas y no los regresaba. Los discos que mandó la mexicana de Tamaulipas, se perdieron en Curicó por culpa de mi hermano (Valenzuela, 2013). 
Nibaldo Valenzuela Fernández se apoyó en su hermana exiliada en Europa. A través de ella, disfrutó de Alma Norteña, Las Palomas, Las Jilguerillas y Mercedes Castro. En sus viajes por México y España, la hermana de Valenzuela compró discos que luego envío a Chile. "Con la dictadura llegaron pocos discos mexicanos, todos de contrabando. Nunca pude hacerme de ninguno porque eran carísimos, te costaban 12 veces más que antes del golpe militar" (Valenzuela, 2013).

La dictadura no sólo trajo el florecimiento de la industria discográfica chilena, especializada en las músicas mexicanas, también motivó el surgimiento de duetos norteños como Los Luceros y Los Reales del Valle. La gente quería escuchar músicas mexicanas. "Si alguien tenía acordeón y guitarra, comenzaba a cantar, y la gente, ávida de momentos felices, lo tiraba para arriba" (Valenzuela, 2012).

Desde lo económico, festivales que se organizan en Chile durante los primeros meses del año explican el auge y masificación de los duetos rancheros chilenos a partir de la década de 1970. Los eventos tienen que ver con el campo, como el Festival del Choclo y la Sandía. "En enero y febrero está el furor de las cosechas. Es verano, hay dinero para contratar a los duetos norteños" (Valenzuela, 2013).

\section{Contra la dictadura}

El locutor Hugo Olivares Carbajal, especialista en géneros musicales de México, nació el 4 de junio de 1962, en Ovalle, norte de Chile. Migró a Santiago en 1967, junto a sus padres. Actualmente, produce y conduce dos programas de música mexicana: Despertar Ranchero y Los Capos de México. El primero es transmitido de lunes a viernes, por las mañanas, en Calipso FM, perteneciente al grupo Radio Colo Colo. Inició en el año 2000, como una idea original del acordeonista norteño Juan Contreras, fundador de Los Rancheros de Río Grande: "Juan me enseñó el valor de la música mexicana. Me dijo que pusiera música 100\% mexicana, yo no tenía nada entonces, así que él traía todo, por eso lo quiero" (Olivares, 2013).

El nombre de Los Capos de México se debe a que "en Chile un capo es el mejor, el bueno, el número uno. La gente sabe que va a escuchar lo mejor de la música mexicana" (Olivares, 2013). Olivares Carvajal aprovechó la música del grupo norteño homónimo para "armar las cortinas". Los Capos de México fue transmitido por primera vez, el 1 de mayo del 2004, en Radio Estación Cuatro de Santiago de Chile. El espacio radiofónico sigue ampliando sus áreas de influencia.

Las grandes radios de Chile no han tocado música mexicana porque "las ven como herencia de Pinochet" (Olivares, 2013). Cuando sucedió el golpe militar del 11 de septiembre de 1973, el locutor chileno, Hugo Olivares Carvajal, tenía 11 años de edad.

Durante el golpe militar hubo artistas que no quisieron venir a Chile. Con Pinochet surgió Radio Colo Colo, se hizo harta música ranchera, lo que pasa es que la música 
Imagen 3. Mariachi mexicano. Recuperado de: https:// mas-mexico.com.mx/diadel-mariachi-el-genero-masrepresentativo-de-mexico/. estereotipo del huaso —ligado al campo_-, los caballos y la cueca (baile tradicional). No es casualidad, que uno de los grupos consentidos de la dictadura fueran Los Huasos Quincheros. Indudablemente la imagen del charro mexicano ayudó en el reforzamiento del estereotipo del huaso, pues ambos actores poseen características similares. En las imágenes 2 y 3 se clarifica este hecho.Géneros musicales y películas mexicanas sin contenido político sirvieron

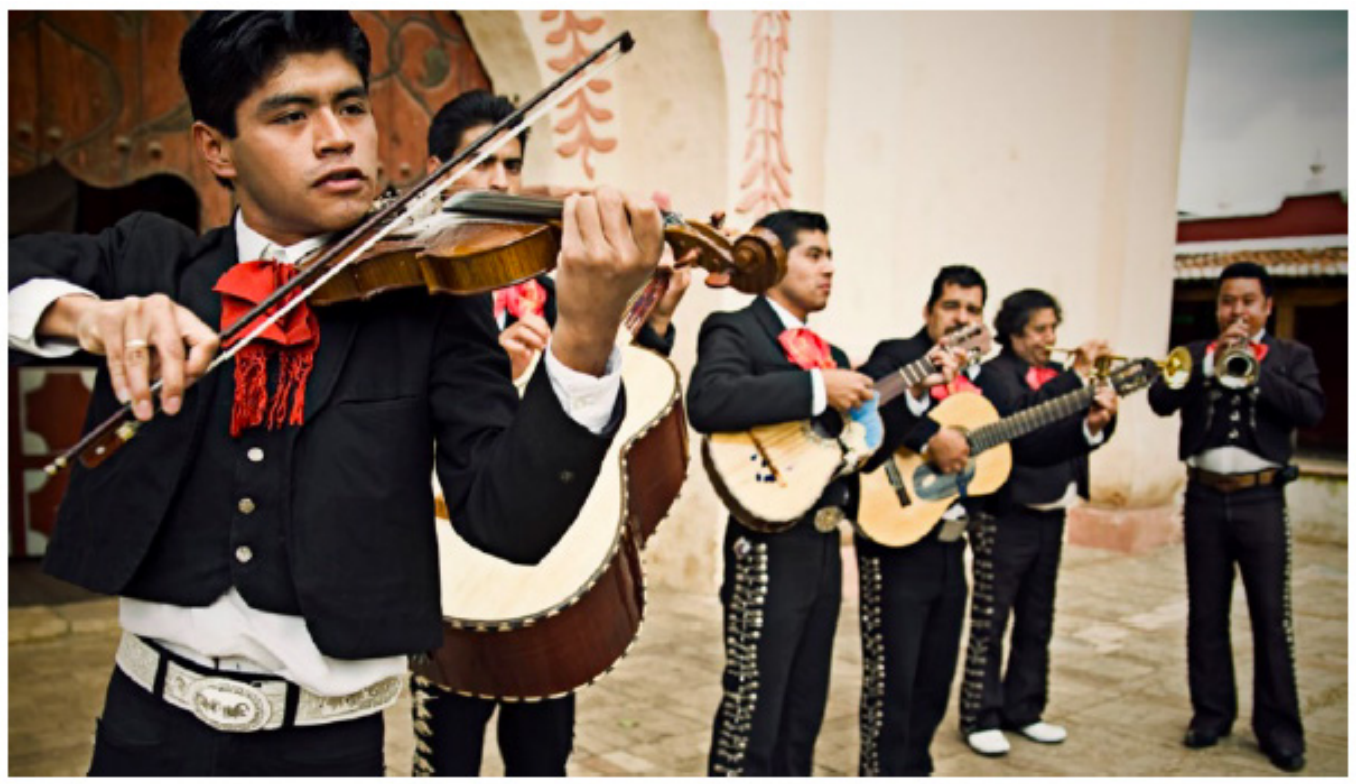

de distractores (el abordaje de la revolución mexicana fue censurado) (Guzmán, 2013). La música mexicana ayudó a reforzar el poder de la dictadura con la gente del campo, sitio donde está enraizado el amor por México. "En el rancho chileno, cantan 'El caballo blanco' y 'La yegua colorada', e ignoraran 'Si vas para Chile"' (Guzmán, 2013).

\section{Conclusiones}

La presencia de la música mexicana en Chile se enmarca en un intercambio comercial y cultural que data, por lo menos, del siglo xIX. La existencia de mexicanos en Chile ha sido un fenómeno constante y sostenido, desde finales del mismo siglo. Porfirio Díaz, por ejemplo, envió un grupo de músicos a la nación trasandina. La injerencia del Estado mexicano en Chile ha sido contundente. Desde el siglo xIx, México ha remitido contingentes de músicos y artistas (David Alfaro Siqueiros, entre ellos). México ha contribuido en las reconstrucciones de Chile, consecuencia de los terremotos que la nación andina ha padecido.

A pesar de que las relaciones políticas y comerciales entre México y Chile se quebraron a raíz de la dictadura, las músicas mexicanas siguieron llegando a la nación trasandina, gracias a la intervención de chilenos exiliados en México, de chilenas radicadas en España, del contrabando y de la tenacidad que mexicanas 
como Imelda Zapata mostraron. Durante la dictadura militar, hubo mexicanos que, viviendo en Chile, promovieron y difundieron la cultura mexicana, en general.

La dictadura militar de Augusto Pinochet Ugarte distanció al pueblo chileno, desgarró su sociedad, mutiló sus lazos comunitarios, volvió antagónicos a los huasos y a los intelectuales. En Chile la música mexicana carga el estigma de ser tratada con desconfianza por los sectores letrados de Chile.

A la par de este fenómeno, los intérpretes más valorados, en términos artísticos, por las élites intelectuales chilenas (Violeta Para, Víctor Jara, Quilapayún y Mauricio Redolés Bustos), han interpretado y grabado música mexicana. Las músicas mexicanas en Chile son anteriores a los gobiernos de Allende y Pinochet. Están más allá de derechas e izquierdas, pero tampoco son privativas de los huasos (pobres, iletrados).

Las élites chilenas, que son quienes escriben la historia de la nación trasandina, se han empeñado en olvidar un pasado estrechamente ligado a México. Niegan la actualidad de prácticas musicales como la norteña y el mariachi, arguyen que la música mexicana es del sur, donde habitan huasos (gente sin educación ni cultura). Christian Maldonado, en su documental, Norteños del Sur, da cuenta de la presencia de este tipo de música en la capital chilena. La realidad que vive la música mexicana en Chile es diferente a lo reproducido por los medios oficiales.

En los círculos universitarios se volvió leyenda el origen sureño de las músicas mexicanas. Al repetirlo, una y otra vez, se distancian de la dictadura pinochetista, la cual asocian con las músicas mexicanas. Para cientos de chilenos universitarios, las músicas mexicanas fueron aliadas del gobierno militar, en el adoctrinamiento de masas, junto con la televisión, la que se convirtió "en una industria de producción y reproducción de mensajes homogeneizadores para el consumo masivo" (Subercaseaux, 2010, 201).

Luego del trabajo de campo realizado en Chile, me percaté que el amor por las músicas mexicanas rebasa los estratos sociales. Antes de llegar a Chile, iba con la idea de un país lleno de gente con rasgos europeos, ajena a la música mexicana. Pensaba que la conexión que explicaría una posible afición de los chilenos por la música norteña estaba en el sur de Chile, por concentrar esta región una importante migración de alemanes y polacos. Imaginé que al ser la música norteña resultado del mestizaje entre el acordeón de origen europeo y el bajo sexto de fabricación mexicana, las migraciones centro-europeas a Chile, podrían ayudar a dilucidar el porqué de la existencia de grupos de música norteña como Sentimiento Norteño de Marco Mañán y Corazón Norteño de Ricardo Rojas. Estaba lejos de imaginar la realidad compleja, profunda y enraizada que representan las músicas mexicanas en Chile. 
Una vez en Santiago, fue muy sencillo comenzar a ubicar mis fuentes. A los tres días de establecido en la capital de Chile, ya había entrevistados a Mario Obando, fabricante de bajo sextos, nacido en Valdivia (sur de Chile), pero radicado en Santiago. Me encontré con el laudero, que me llevó por algunas picadas o cantinas de Santiago (El Hoyo y La Piojera), sitios donde las músicas mexicanas están presentes. Son lugares pensados para el turismo. En La Piojera, están Los Soles del Norte, dueto de música norteña formado por talentos chilenos. El dueto tiene más de 40 años divulgando la música norteña mexicana en La Piojera de Santiago.

Con el triunfo del NO y la elección del primer gobierno de la concertación en 1989, se inició una nueva época para Chile. Es natural y entendible que luego de las vejaciones sufridas por la dictadura, los chilenos quisieran alejarse de todo lo que oliera a Pinochet. Lamentablemente, las músicas mexicanas forman parte de ese patrimonio inmaterial heredado por la dictadura pinochetista. El proceso de alianza entre la dictadura de Pinochet y la música mexicana tendría que estudiarse con mayor profundidad en trabajos futuros. La dictadura de Augusto Pinochet Ugarte es una herida abierta, y también una oportunidad para que la nación chilena aclare dudas y responda preguntas sobre su pasado inmediato.

\section{Referencias y fuentes consultadas}

* Bustos, Fernando [entrevista]. (2012). Por Luis Omar Montoya Arias [trabajo de campo], Memoria, Migración y Nacionalismo. La construcción histórica de la música norteña mexicana.

* Guzmán, Ingrid [entrevista]. (2013). Por Luis Omar Montoya Arias [trabajo de campo], Memoria, Migración y Nacionalismo. La construcción histórica de la música norteña mexicana.

* Inzunza, Oscar [entrevista]. (2012). Por Luis Omar Montoya Arias [trabajo de campo], Memoria, Migración y Nacionalismo. La construcción histórica de la música norteña mexicana.

* Larraín, Jorge (2001), Identidad chilena, Lom Ediciones.

* Méndez, Fernando [entrevista]. (2012). Por Luis Omar Montoya Arias [trabajo de campo], Memoria, Migración y Nacionalismo. La construcción histórica de la música norteña mexicana.

- Olivares, Hugo [entrevista]. (2012 y 2013). Por Luis Omar Montoya Arias [trabajo de campo], Memoria, Migración y Nacionalismo. La construcción histórica de la música norteña mexicana.

- Subercaseaux, Bernardo (2010), Historia del libro en Chile, Lom Ediciones. 
* Valenzuela, Nibaldo [entrevista]. (2012 y 2013). Por Luis Omar Montoya Arias [trabajo de campo], Memoria, Migración y Nacionalismo. La construcción histórica de la música norteña mexicana.

* Zúñiga Cortés, Sergio [entrevista]. (2013) Por Luis Omar Montoya Arias [trabajo de campo], Memoria, Migración y Nacionalismo. La construcción histórica de la música norteña mexicana.

\section{Cómo citar este artículo}

* Montoya, Arias, Luis Omar y Solís García, Karla Liebed (2020). La influencia cultural a través de la música mexicana: rancheras en Chile. Revista Digital Universitaria (RDU). Vol. 21, núm. 3 mayo-junio. Dol: http://doi.org/10.22201/codeic.16076079e.2020. v21n3.a1.

Recepción: 18/11/2016. Aceptación: 02/10/2019. 